\title{
КАДАСТРОВЫЕ РАБОТЫ В ОТНОШЕНИИ ОБЪЕКТОВ КАПИТАЛЬНОГО СТРОИТЕЛЬСТВА: ПРОБЛЕМЫ И ПУТИ ИХ РЕШЕНИЯ
}

\section{Ильгиз Ахатович Гиниятов}

Сибирский государственный университет геосистем и технологий, 630108, Россия, г. Новосибирск, ул. Плахотного, 10, кандидат технических наук, доцент, доцент кафедры кадастра и территориального планирования, тел. (383)344-31-73, e-mail: kadastr204@yandex.ru

\section{Елена Валерьевна Меркулова}

Сибирский государственный университет геосистем и технологий, 630108, Россия, г. Новосибирск, ул. Плахотного, 10, аспирант, тел. (383)362-47-10, e-mail: snowflexmev@mail.ru

В статье рассмотрены основные проблемы, возникающие при выполнении кадастровых работ в отношении объектов капитального строительства (ОКС), определены их причины и показаны возможные пути решения. Рассмотрены основные принципы выполнения кадастровых работ в отношении ОКС и возможные последствия их несоблюдения. Сделан вывод о необходимости разработки единой методики выполнения кадастровых работ в отношении всех видов ОКС и единой системы нормативных правовых актов, призванных регламентировать процедуру кадастровых работ.

Ключевые слова: кадастровые работы, объект недвижимости, объект капитального строительства, Единый государственный реестр недвижимости, принцип, описание характеристик объекта, требования, правовой статус, методика

\section{CADASTRAL WORKS WITH RESPECT TO CAPITAL CONSTRUCTION OBJECTS: PROBLEMS AND WAYS OF THEIR SOLUTION}

\section{Ilgiz, A. Giniyatov}

Siberian State University of Geosystems and Technologies, 10, Plakhotnogo St., Novosibirsk, 630108, Russia, Ph. D., Associate Professor, Department of Cadastre and Territorial Planning, phone: (383)344-31-73, e-mail: kadastr204@yandex.ru

\section{Elena V. Merkulova}

Siberian State University of Geosystems and Technologies, 10, Plakhotnogo St., Novosibirsk, 630108, Russia, Ph. D. Student, phone: (383)362-47-10, e-mail: snowflexmev@mail.ru

The article discusses the main problems that arise when performing cadastral works in relation to capital construction objects (ACS), identifies their causes and shows possible solutions. The basic principles of the cadastral work in relation to the ACS and the possible consequences of their non-observance are considered. It is concluded that it is necessary to develop a unified methodology for performing cadastral work in relation to all types of ACS and a unified system of regulatory legal acts designed to regulate the procedure for cadastral work.

Keywords: cadastral works, real estate object, capital construction object, Unified State Register of Real Estate, principle, description of object characteristics, requirements, legal status, methodology 
1 января 2013 года государственный технический учет и техническая инвентаризация объектов капитального строительства (ОКС), обеспечивавшие гражданский оборот недвижимости, были заменены государственным кадастровым учетом (ГКУ) зданий, сооружений, помещений, объектов незавершенного строительства и кадастровой деятельностью в отношении перечисленных объектов. Указанная дата послужила началом осуществления на всей территории России ГКУ ОКС. Положения нормативно-правовых актов (НПА) в сфере осуществления государственного технического учета и технической инвентаризации ОКС с указанной даты перестали применяться. Официальным источником сведений о зданиях, сооружениях, помещениях и объектах незавершенного строительства стал Государственный кадастр недвижимости (ГКН) [1].

В настоящее время одним из основных документов, необходимых для постановки на ГКУ здания, сооружения, помещения или объекта незавершенного строительства, является технический план, форма, содержание и требования к оформлению которого, регламентируются приказами Минэкономразвития России № 953 от 18 декабря 2015 года [2] и № 90 от 1 марта 2016 года [3]. Указанная форма технического плана объекта недвижимости $(\mathrm{OH})$ содержит в себе всю необходимую информацию о таком $\mathrm{OH}$ для последующего внесения в Единый государственный реестр недвижимости (ЕГРН) сведений о таком объекте, состав которых регламентируется законом о регистрации недвижимости [4].

На сайте Правительства Российской Федерации было опубликовано Постановление о признании утратившими силу некоторых решений Правительства РФ по вопросам осуществления государственного технического учета и технической инвентаризации ОКС от 3 июля 2013 г. [5], подготовка которого была осуществлена Минэкономразвития РФ в рамках исполнения требований федерального закона о ГКН, регламентируемых статьями 43 ч. 1 и 47 ч. 8 . С принятием федерального закона о внесении изменений в отдельные законодательные акты Российской Федерации [6] была введена в действие новая редакция указанных частей в статьях закона о ГКН, которая определила, что с 1 января 2013 г. перестают применяться положения НПА в сфере технической инвентаризации и осуществления государственного технического учета ОКС. Иными словами, на всей территории России осуществление ГКУ ОКС стало регламентироваться нормами федерального закона о ГКН.

В связи с изменениями в законодательстве отдельные решения Правительства РФ, ранее регулировавшие отношения в сфере организации технической инвентаризации и государственного технического учета ОКС, были признаны утратившими силу как не соответствующие действующему порядку осуществления ГКУ. Прежде всего, это относится к Положению об организации в РФ государственного технического учета и технической инвентаризации ОКС [7], а также к ряду Постановлений Правительства, которые вносили изменения в указанное Положение и некоторые акты Правительства РФ по вопросам осуществления государственного технического учета и технической инвентаризации ОКС [8-12]. 
Таким образом, с 1 января 2013 г. получение сведений об ОКС, равно как и их актуализация, осуществляется в результате проведения кадастровых работ в отношении вышеперечисленных объектов недвижимости.

Основываясь на вышеизложенном, мы вправе утверждать, что институт кадастровой деятельности в отношении ОКС в России является сравнительно молодым. Практика выполнения кадастровых работ в отношении ОКС и подготовки кадастровыми инженерами соответствующих документов для осуществления ГКУ ОКС стала формироваться с 2013 года, насчитывая, на сегодняшний день, неполные 8 лет. Однако, несмотря на это, нередко имеют место проблемы, возникающие как в процессе выполнения кадастровых работ, так и при осуществлении ГКУ ОКС.

Закон о кадастровой деятельности [13] закрепил базовые принципы, соблюдение которых является обязанностью кадастрового инженера, а несоблюдение - серьезным нарушением. Сущность этих принципов заключается в следующем:

- ОН, в отношении которого предполагается выполнение кадастровых работ, не является объектом недвижимости, подлежащим ГКУ;

- предоставленные заказчиком кадастровых работ документы по форме и (или) по содержанию не соответствуют требованиям законодательства Российской Федерации, действовавшего в момент их издания и в месте их издания;

- предоставленные заказчиком документы содержат недостоверные сведения.

Соблюдение этих принципов в значительной степени зависит от понимания кадастровым инженером конкретных действий и алгоритмов, которые ему необходимо осуществить при выполнении кадастровых работ для получения необходимых сведений об $\mathrm{OH}$, позволяющих однозначно определить такой объект в качестве индивидуально-определенной вещи и подтвердить его существование с теми или иными характеристиками. Однако, необходимо отметить, что действующие НПА в сфере кадастровых отношений не описывают в полной мере всю процедуру выполнения кадастровых работ, все те действия, с которыми на практике приходится сталкиваться кадастровому инженеру. Закон о кадастровой деятельности [13] указывает лишь на часть выполняемых кадастровыми инженерами работ в отношении ОКС: определение координат характерных точек контура здания, сооружения, или их частей и контура объекта незавершенного строительства, обработка результатов определения таких координат, в ходе которой вычисляется площадь ОКС и осуществляется описание их местоположения. Фактически же, кадастровые инженеры сталкиваются с необходимостью решения более широкого круга вопросов, требующих от них выполнения иных, непрофильных для кадастровых инженеров, работ, действий, исследований.

Так для определения принадлежности конкретного ОН к объектам недвижимости, подлежащим ГКУ, кадастровый инженер должен был бы руководствоваться соответствующей инструкцией или методикой, позволяющей 
установить такую прочную связь ОН с землей, которая повлечет несоразмерный ущерб назначению ОН при его перемещении. Однако, действующее законодательство РФ не содержит алгоритмов, позволяющих рассчитать несоразмерность ущерба и провести оценку такого признака ОН как прочная связь с землей. Практика показала, что при выполнении кадастровых работ, как правило, проводится субъективная оценка физической связи с землей на предмет ее прочности: насколько прочно объект связан с землей фундаментом, насколько фундамент заглублен в землю, насколько прочно связан фундамент объекта с его несущими конструкциями. При этом, основной признак прочности связи с землей - несоразмерность ущерба назначению ОН при его перемещении никак не оценивается в связи с отсутствием утвержденных расчетных и нормативных показателей для такой оценки.

На рис. 1 приведены исторические снимки, свидетельствующие о наличии технологий, позволяющих переместить объект недвижимости, что само по себе, не может служить основанием для признания изображенных на снимках объектов движимыми вещами. Следовательно, понятие недвижимости требует оценки и исследования такого показателя, как ущерб назначению объекта, вызванный его перемещением, как его несоразмерность (степень значимости для конкретного правообладателя).
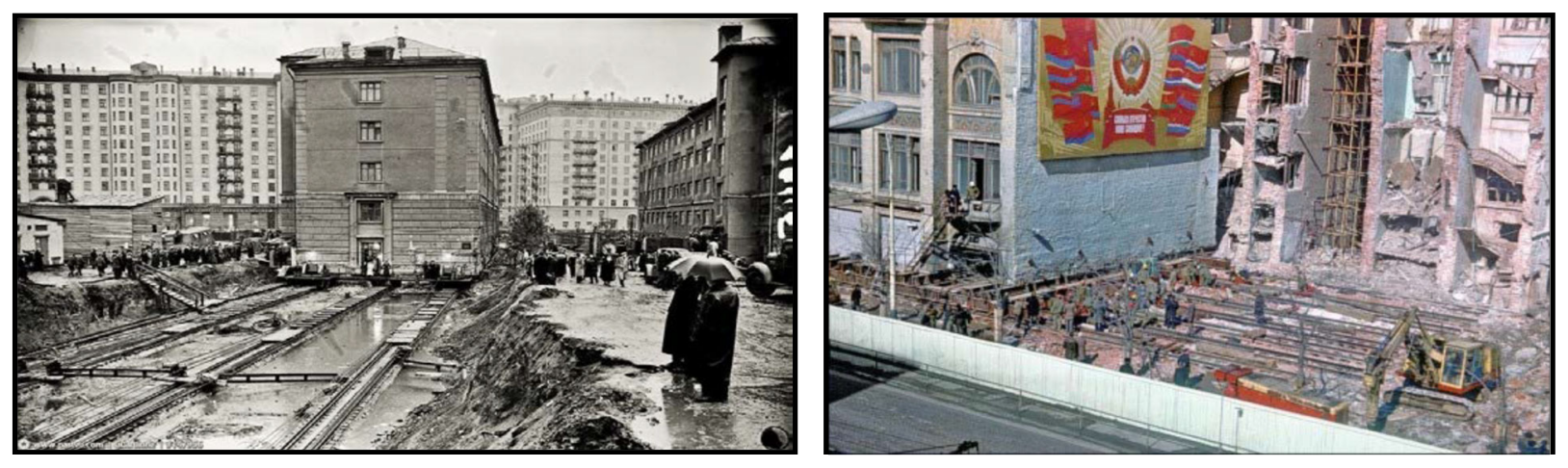

Рис. 1. Перемещение многоквартирных домов

Для анализа документов, предоставленных заказчиком кадастровых работ, на их соответствие по форме и (или) содержанию требованиям законодательства РФ, кадастровым инженерам нередко приходится привлекать юристов, так как сами они, зачастую, не обладают достаточным уровнем юридических знаний для такого анализа.

Осуществить проверку предоставленных заказчиком документов на предмет достоверности содержащихся в них сведений, как показывает практика, в отсутствие закрепленного в действующем законодательстве РФ понятия достоверности сведений весьма затруднительно. При этом отсутствует четкое представление о том, какие именно сведения в документе подлежат проверке и относительно чего проводится их проверка. Если такую проверку осуществлять путем сравнения фактических сведений об ОН, полученных по результатам выезда кадаст- 
рового инженера на местность, и сведений о данном объекте, содержащихся в документах, представленных заказчиком, то для проведения такого сравнительного анализа кадастровому инженеру опять потребуется инструкция или методика, которая позволила бы не только определить правовой статус $\mathrm{OH}$, но и с высокой степенью однозначности описать характеристики такого объекта, и, следовательно, своевременно выявить несоответствие сведений об ОН обеспечив, тем самым, внесение в ЕГРН достоверных сведений об ОН.

Отсутствие в действующем законодательстве РФ методик (инструкций, правил, рекомендаций) выполнения кадастровых работ в отношении ОКС не позволяет осуществлять кадастровую деятельность в соответствии с заложенными в Законе о кадастровой деятельности [13] принципами.

Для визуализации изложенной проблематики на рис. 2 приведены фотоматериалы внеплановых проверок саморегулируемой организации кадастровых инженеров, в рамках которых осуществлялась проверка кадастровой деятельности членов такой организации при выполнении кадастровых работ по данным объектам.

В процессе осуществления кадастровой деятельности по данным объектам кадастровому инженеру необходимо было принять одно из следующих решений:

- выполнять ли в отношении объекта кадастровые работы;

- если выполнять, то, каким образом определять характеристики объекта с целью их описания в техническом плане, подготавливаемом по результатам кадастровых работ.
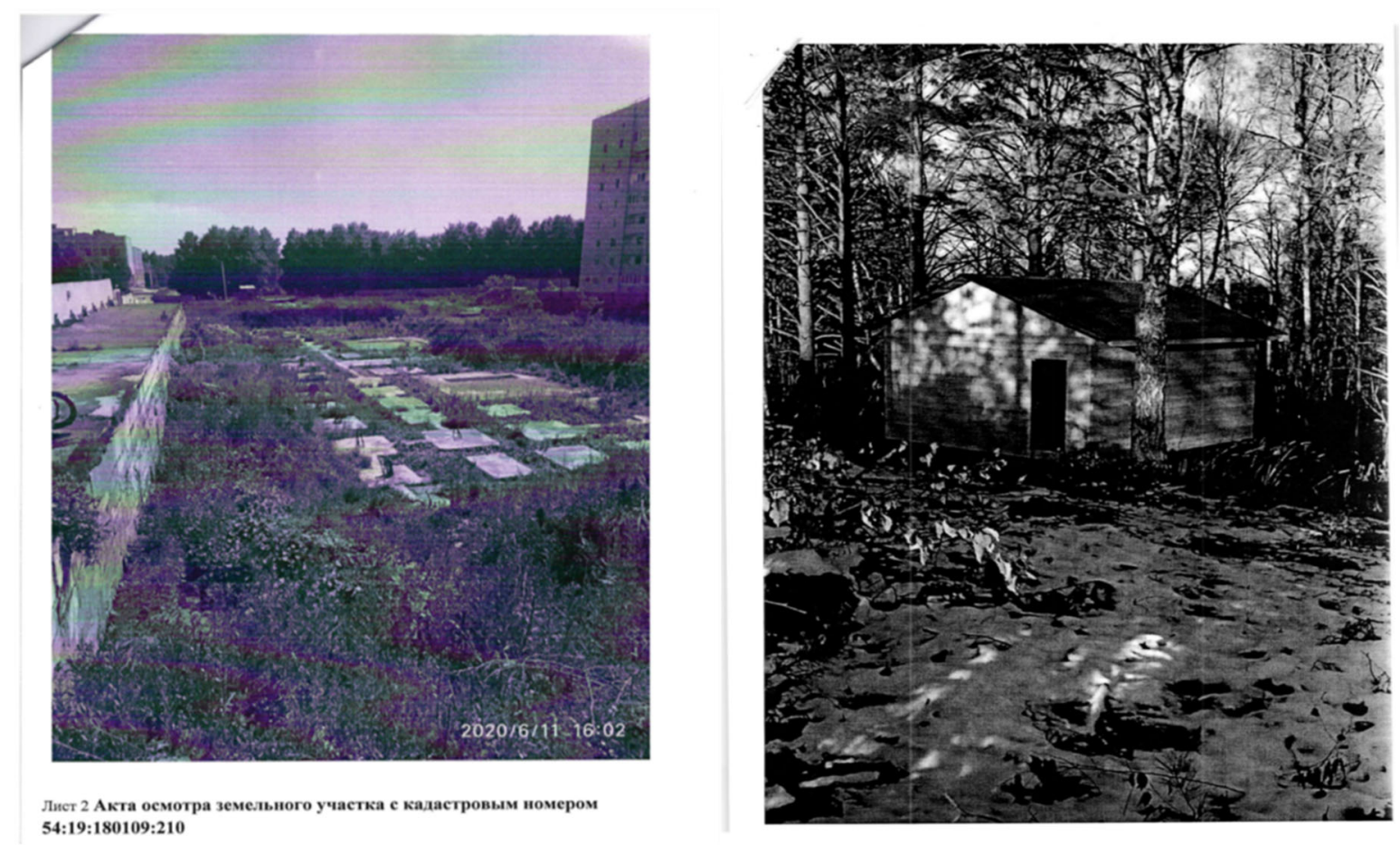

Рис. 2. Фотоматериалы объектов кадастровых работ 
Кроме того, кадастровый инженер должен был решить еще несколько задач. Для объекта, изображенного на левом снимке, необходимо было определить следующее:

- выбрать для изображенного на фото объекта соответствующий вид и определить степень завершенности его строительства (здание или объект незавершенного строительства);

- определить назначение ОН (жилой или нежилой).

Для объекта, изображенного на правом снимке, необходимо было определить следующее:

- степень готовности конструктивных элементов объекта;

- является ли объект ОН, подлежащим ГКУ.

По результатам исследования фотоматериалов были сделаны следующие выводы:

- в отсутствие методики, позволяющей определить параметры (признаки) завершенности строительства объекта, назначения объекта, несоразмерности ущерба назначению объекта при его перемещении, невозможно однозначно установить какой правовой статус имеет объект и какие характеристики определяют его в качестве индивидуально-определенной вещи;

- в отсутствие методики, позволяющей установить при какой минимальной степени готовности конструктивных элементов объект будет считаться объектом недвижимости, подлежащим ГКУ, при отсутствии понятия объекта незавершенного строительства, в т. ч. установить несоразмерность ущерба назначению объекта при его перемещении, невозможно однозначно установить какой правовой статус имеет объект и какие характеристики определяют его в качестве индивидуально-определенной вещи.

При осуществлении кадастровой деятельности в отношении объектов индивидуального жилищного строительства кадастровым инженерам необходимо, помимо перечисленных вопросов, установить правовой статус объекта в соответствии с закрепленным в законодательстве РФ понятием объекта: определить, что построено - жилой дом или иной объект недвижимости.

Визуализация возникающих у кадастровых инженеров вопросов при выполнении кадастровых работ в отношении жилых домов приведена на рис. 3.

Сущность этих вопросов заключается в следующем:

- каким способом, по какой методике, с какой точностью определить высоту построенного объекта с целью возможности отнесения объекта к жилому дому (объекту индивидуального жилищного строительства);

- где в техническом плане (в каких реквизитах) необходимо отразить сведения о такой характеристике $\mathrm{OH}$, как высота;

- как определить предназначены или нет помещения $\mathrm{OH}$ для раздела на самостоятельные $\mathrm{OH}$, то есть те, которые могут участвовать в гражданском обороте недвижимости в качестве самостоятельных вещей.

При выполнении кадастровых работ в отношении объектов, не требующих выдачи разрешения на строительство, кадастровые инженеры в целях исключения необходимости истребования с заказчика дополнительных документов, 
должны каким-то образом, в отсутствие установленных критериев и признаков, определить:

- используется ли ОН для предпринимательских или личных целей, если таковым ОН является гараж, построенный на земельном участке, отведенном для строительства индивидуального гаража;

- является ли ОН объектом вспомогательного использования (для целей обслуживания какого основного объекта строился, какое имеет функциональное назначение);

- является ли объект кадастровых работ сооружением, подлежащим кадастровому учету в качестве самостоятельного объекта недвижимости, либо является частью сооружения, не имеющей самостоятельного назначения и классифицируемой как движимая вещь (например, сооружение трубопровода от источника передачи до точки потребления либо часть трубопровода - труба как движимая вещь).

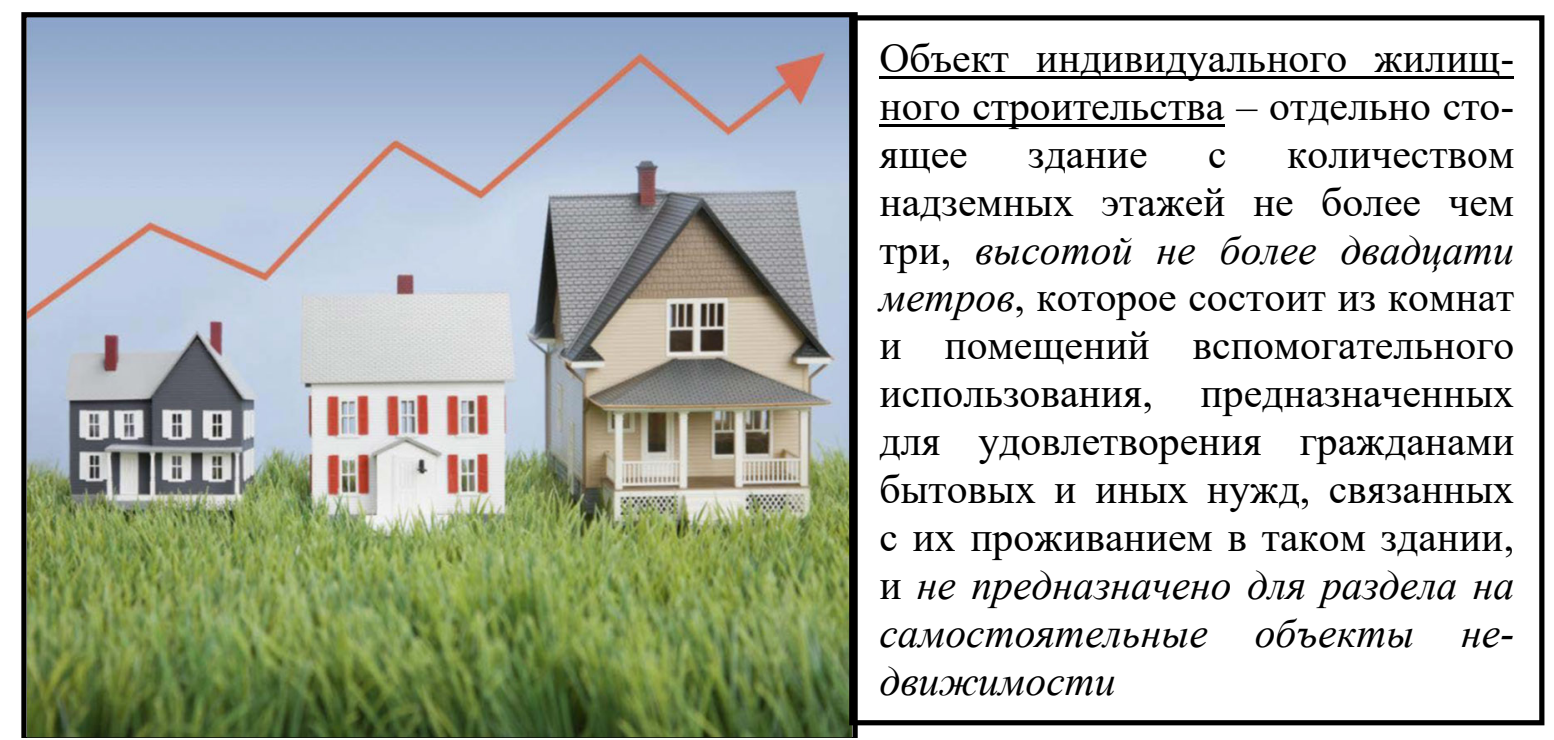

Рис. 3. Объект недвижимости - жилой дом или иной объект

Существующая практика выполнения кадастровых работ в отношении ОКС наглядно иллюстрирует тот факт, что отсутствие единой комплексной методики ведения кадастровых работ в отношении всех видов ОКС, как правило, приводит к различным результатам их выполнения при наличии одних и тех же исходных данных. Объяснение этому кроется в применении кадастровыми инженерами субъективного подхода, напрямую обусловленного отсутствием единых требований и правил проведения кадастровых работ в отношении ОКС, инструкций и рекомендаций по определению тех или иных параметров и характеристик ОН. Все эти документы могли бы найти свое отражение в единой системе НПА, регламентирующе процедуру кадастровых работ.

Вышеперечисленные обстоятельства не позволяют осуществлять кадастровую деятельность в отношении ОКС в соответствии с заложенными в Законе о кадастровой деятельности [13] принципами и приводят к возникновению различного рода рисков: 
- аналогичный субъективный подход применяется не только при выполнении кадастровых работ, но и в последующем - при оценке действий кадастровых инженеров по определению правового статуса объекта, его параметров и характеристик судебными и правоохранительными органами, Росреестром;

- установление вины кадастровых инженеров с применением мер уголовной или административной ответственности за недостоверность сведений об $\mathrm{OH}$, отраженных в техническом плане;

- возникновение материального ущерба для государства, заказчиков кадастровых работ или иных заинтересованных лиц.

Разработка Единой методики выполнения кадастровых работ в отношении ОКС позволит, на наш взгляд, установить единые требования к выполнению кадастровых работ в отношении разных видов ОКС, закрепить перечень необходимых процедур (действий, обследований), параметров и характеристик $\mathrm{OH}$, подлежащих определению кадастровым инженером (вид $\mathrm{OH}$, назначение, включая функциональное, степень завершенности строительства объекта, способы расчета или анализа иных параметров $\mathrm{OH}$, имеющих значение для результата кадастровых работ), определить круг обязательных участников и закрепить необходимые для них правила, а также будет способствовать объективному подходу при выполнении кадастровыми инженерами кадастровых работ и, как следствие, достоверности сведений об объекте. Помимо этого, Единая методика позволит также компенсировать неполноту и несовершенство действующего законодательства РФ в области кадастровых отношений.

\section{БИБЛИОГРАФИЧЕСКИЙ СПИСОК}

1. Федеральный закон от 24.07.2007 № 221-Ф3 «О государственном кадастре недвижимости».- Режим доступа: http://www.garant.ru.

2. Приказ Минэкономразвития России от 18 декабря 2015 года № 953«Об утверждении формы технического плана и требований к его подготовке, состава содержащихся в нем сведений, а также формы декларации об объекте недвижимости, требований к ее подготовке, состава содержащихся в ней сведений»).-Режим доступа: http://www.garant.ru.

3. Приказ Минэкономразвития России от 01.03.2016 № 90 "Об утверждении требований к точности и методам определения координат характерных точек границ земельного участка, требований к точности и методам определения координат характерных точек контура здания, сооружения или объекта незавершенного строительства на земельном участке, а также требований к определению площади здания, сооружения и помещения" (Зарегистрировано в Минюсте России 08.04.2016 № 41712).-Режим доступа: http://www.garant.ru.

4. Федеральный закон от 13.07.2015 № 218-Ф3 "О государственной регистрации недвижимости". Режим доступа: http://base.garant.ru/71129192.

5. Постановление Правительства РФ от 27.06.2013 г. № 546 «О признании утратившими силу некоторых решений Правительства Российской Федерации по вопросам осуществления государственного технического учета и технической инвентаризации объектов капитального строительства».- Режим доступа: http://www.garant.ru.

6. Федеральный закон от 21.12.2009 г. № 334-Ф3 «О внесении изменений в отдельные законодательные акты Российской Федерации» .-Режим доступа: http://www.garant.ru.

7. Постановление Правительства РФ от 04.12.2000 г. № 921 «О государственном техническом учете и технической инвентаризации в Российской Федерации объектов капитального строительства» .- Режим доступа: http://www.garant.ru. 
8. Постановление Правительства РФ от 28.12.2006 г. № 818 «О внесении изменения в Положение об организации в Российской Федерации государственного технического учета и технической инвентаризации объектов капитального строительства, утвержденное постановлением Правительства Российской Федерации от 4 декабря 2000 года № 921» .- Режим доступа: http://www.garant.ru.

9. Постановление Правительства РФ от 21.12.2010 г.№ 644 «О внесении изменений в Положение об организации в Российской Федерации государственного технического учета и технической инвентаризации объектов капитального строительства» .- Режим доступа: http://www.garant.ru.

10. Постановление Правительства РФ от 10.09.2004 г.№ 477 «О внесении изменений в некоторые акты Правительства Российской Федерации по вопросам осуществления государственного технического учета и технической инвентаризации объектов капитального строительства» .- Режим доступа: http://www.garant.ru.

11. Постановление Правительства РФ от 19.03.2005 г. № 141 «О внесении изменений в некоторые постановления Правительства Российской Федерации по вопросам осуществления государственного технического учета и технической инвентаризации объектов градостроительной деятельности» .- Режим доступа: http://www.garant.ru.

12. Постановление Правительства РФ от 30.04.2009 г. № 388 «О внесении изменений в постановления Правительства Российской Федерации от 4 декабря 2000 г. № 921 и от 13 октября 1997 г. № 1301» .- Режим доступа: http://www.garant.ru.

13. Федеральный закон от 24.07.2007 № 221-Ф3 «О кадастровой деятельности».- Режим доступа: http://www.garant.ru.

(C) И. А. Гиниятов, Е. В. Меркулова, 2021 